\title{
Modified learning set performance as a function of age ${ }^{1,2}$
}

ROBERT J. WEBER

KENYON COLLEGE

\begin{abstract}
A modified learning task in which each problem contained recurrent and nonrecurrent stimulus forms was administered to age groups $6,8,10$, and 12 years. For each age group a correct choice based on the nonrecurrent stimuli was more difficult than a correct choice based on the recurrent stimuli.
\end{abstract}

\section{Introduction}

In the animal literature learning set procedures for object-quality discriminations have proven valuable for distinguishing among species (Harlow, 1959) and also for distinguishing across ages within a given species (Harlow, Harlow, Reuping, \& Mason, 1960).

In the present study a modified learning set task is used to distinguish across ages when human Ss are employed. The modified task and the results obtained with it then give rise to several interesting interpretive questions.

\section{Method}

Subjects. A total of 80 public elementary school children from Mt. Vernon, Ohio served as Ss. The age breakdown of $20 \mathrm{Ss}$ each from grades $6,4,2$, and kindergarten was as follows. The age of the sixth graders ranged from 11-11 to 12-6, median age 12-3 (hereafter this will be referred to as group 12). The fourth graders ranged from 9-11 to 10-6, median age 10-2 (group 10). The second graders ranged from 8-0 to 8-5, median age 8-2 (group 8). And the kindergarteners ranged from 5-11 to 6-6, median age 6-3 (group 6). For motivational purposes each $\mathrm{S}$ was given a deck of toy cards at the close of his experimental session.

Stiniili and Display Content. The stimuli used were two-dimensional visual nonsense forms that were designed to be highly distinct from one another; hence they resemble in function the stimuli used in primate learning set studies.

On each trial there were two stimulus elements (each about the size of a fifty-cent piece) with a space of about 3 in between them. They were arrayed horizontally on a $4 \times 6$ card mounted in a visible file folder (Gagne \& Brown, 1961). On each card one stimulus was "recurrent" (R) because it occurred on each trial of the given four-trial problem, and the other stimulus was "nonrecurrent" (NR) because it changed from trial to trial within a problem. Thus no two problems ever had the same recurrent stimulus, and no two trials within a problem ever had the same nonrecurrent stimulus. In Table 1 letters of the alphabet represent individual nonsense forms, and problem 1 has "a"' as
TABLE I

Schematic Representation of Display Content; and Reinforcement Pattern for $\mathbf{R}$ and NR Treatments

\begin{tabular}{|c|c|c|c|c|}
\hline \multirow[b]{2}{*}{ Problem } & \multirow[b]{2}{*}{ Trial } & \multirow[b]{2}{*}{ Display } & \multicolumn{2}{|c|}{ Correct Choice } \\
\hline & & & Recurrent (R) & Nonrecurrent (NR) \\
\hline \multirow[t]{4}{*}{1} & 1 & $a b$ & $a$ & $b$ \\
\hline & 2 & ac & $a$ & $c$ \\
\hline & 3 & da & $a$ & $d$ \\
\hline & 4 & ea & $a$ & e \\
\hline \multirow[t]{4}{*}{2} & 1 & $\mathrm{fg}$ & $f$ & $g$ \\
\hline & 2 & hf & $f$ & $h$ \\
\hline & 3 & $\mathrm{fi}$ & $f$ & i \\
\hline & 4 & if & $f$ & i \\
\hline . & $\cdot$ & . & . & . \\
\hline · & $\cdot$ & · & · & . \\
\hline 38 & $\cdot$ & $\cdot$ & $\cdot$ & $\cdot$ \\
\hline
\end{tabular}

the recurrent stimulus and "b," "c," "d," and "e" as the successive nonrecurrent stimuli. The recurrent and nonrecurrent stimuli are defined analogously for the remainder of the 38 problems. It is clear that this is standard learning set procedure, except for the substitution of nonrecurring stimuli for each appearance of one of the two recurring stimuli in the usual learning set problem.

Procedure. Instructions were minimal and served to acquaint $\mathrm{S}$ with only response and reinforcement procedures. All Ss were run individually. All Ss saw exactly the same displays in exactly the same order, one at a time. The only distinction among conditions resided in the way reinforcement was assigned in treatments $\mathbf{R}$ and NR. In $\mathbf{R}$ groups if an $\mathrm{S}$ pointed to the recurrent stimulus element on a card, he was told "Right" (a choice of a nonrecurrent element produced "Wrong"); he then turned to the next card, made another choice, was told right or wrong, and so on for all 38 problems. In NR groups the same procedure was employed except that choices of the nonrecurrent element were right.

Ss in each of the four age groups were randomly assigned to either treatment $R$ or to NR. The result was a $2 \times 4$ factorial design, $\mathrm{N}=10$ per group.

\section{Results}

Figure 1 gives percent correct choices as a function of trial number. Age in years serves as the parameter. This is a different parameter than the successive problem blocks usually employed by Harlow. The reason for the present practice is brought out in the discussion section. Each point in the figure corresponds to 380 elementary events (10 Ss x 38 problems). Inspection reveals considerable differences between $R$ and 
NR treatments, $\mathbf{R}$ being easier. The age variable is also effective; the older the $\mathrm{S}$ group the better it does. After age 6, performance becomes relatively stable for R groups. By way of contrast the NR treatment results show rapid improvement up to age 10; thereafter performance seems stable. In brief, relatively stable performance for the $\mathbf{R}$ groups occurs about two years earlier than for NR groups.

Summary error statistics for combined trials 2-4 of each problem are presented in Table 2. Each statistic is based on 1140 events ( 3 trials $x 38$ problems $x 10 \mathrm{Ss})$. The difference between $\mathrm{R}$ and NR treatments is significant $(F=22.42, \mathrm{df}=1 / 72, \mathrm{p}<.001)$. There are also significant differences associated with age $(\mathrm{F}=17.48, \mathrm{df}=3 / 72, \mathrm{p}<.001)$. This is in accord with the monotonic decreasing error function in Table 1. Finally, the differences are consistent, so that no significant interaction effects occur $(F=1.91, d f=3 / 72, p>.05)$.

\section{Diseussion}

The obtained results clearly show that modified learning set tasks tap human intellectual abilities that develop with age. What is the theoretical import of this?

In the article by Harlow et al (1960) it is stated that the rhesus monkey's ability to learn single objectdiscrimination problems develops progressively until about 150 days of age. At or beyond that age performance becomes stable and rapid, naive monkeys making an average of about 7.0 to 7.5 errors before criterion learning occurs. The point is underscored that unlike rats and various lower primates a naive rhesus monkey of sufficient maturity has very little difficulty in learning a single discrimination problem. This is in contrast to the authors' statement with respect to learning set acquisition: "no animal acquires this capability without extensive practice." (p. 120) While the statement does seem true of monkeys (which was probably all Harlow intended), the results of the present study cast doubt on it where humans are concerned. It seems that learning set formation can occur in humans without extensive practice (just as single object-discrimination occurs in rhesus monkeys in the absence of extensive practice). One may of course

TABLE 2

Means and SDs for Errors on Combined Trials 2-4

( $\mathbf{N}=\mathbf{1 0}$ for each group)

Group

\begin{tabular}{lllllllll} 
& \multicolumn{8}{c}{ Group } \\
\cline { 2 - 8 } & R-6 & R-8 & R-10 & R-12 & NR-6 & NR-8 & NR-10 & NR-12 \\
\hline Mean & 21.6 & 7.4 & 6.8 & 2.3 & 41.8 & 25.5 & 11.5 & 10.6 \\
SD & 16.06 & 5.26 & 7.25 & 1.79 & 12.54 & 20.52 & 8.70 & 7.79
\end{tabular}

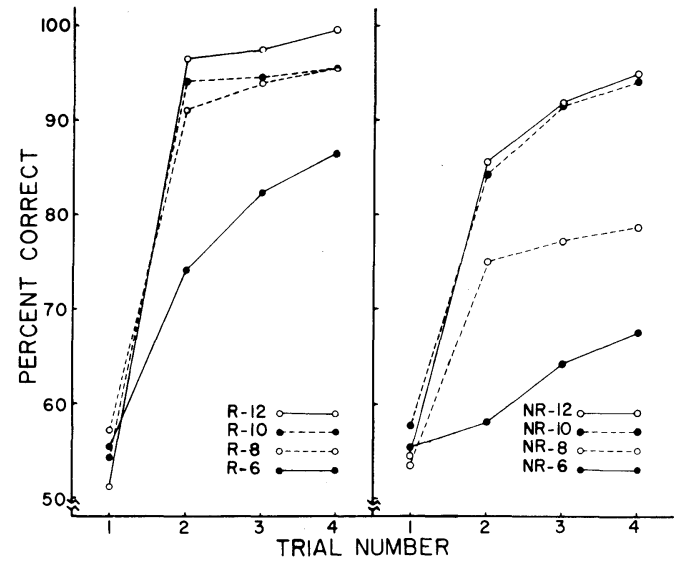

Fig. 1. Percent correct choices as a function of trial number. Age in years is the parameter. Recurrent $(R)$ groups appear in the left panel. Nonrecurrent (NR) groups appear in the right panel.

bring in special ad hoc assumptions to the effect that Ss in their uncontrolled extralaboratory experience gained practice with tasks and materials like those in the present study. But in view of the unlifelike character of the present tasks and materials this seems remote indeed. Also, if such extralaboratory experience is important, in the case of the $R$ groups why is it not available at age 6 when it seems to be available from age 8 on? Similarly, in the case of the NR groups why is it not available at age 6 , and to a lesser extent unavailable at age 8 , and then available from 10 on? While the argument is not airtight, it is a reasonable conclusion that human Ss of sufficient maturity can form learning sets without extensive practice on learning setproblems or everyday materials resembling them. Question: if this conclusion is correct, what implications does it have for Harlow's 1959 explanation of insight in terms of learning set formation?

\section{References}

Gagne, R. M., \& Brown, L. T. Some factors in the programing of conceptual learning. J. exp. Psychol., 1961, 62, 313-321.

Harlow, H. F. Learning set and error factor theory. In S. Koch (Ed.), Psychology: a study of science. New York: McGraw-Hill, 1959. Pp. 492-537.

Harlow, H. F. Harlow, M. K., Rueping, R. R. \& Yason, W. A Performance of infant rhesus monkeys on discrimination learning, delayed response, and discrimination learning set. J. comp. physiol. Psychol., 1960, 53, 113-121.

\section{Notes}

1. This research was supported by National Institutes of Health Grant MH 10725-01.

2. The writer wishes to acknowledge the assistance of Thomas Bowers for running Ss and Barry Wood for help in data reduction. The writer also wishes to thank Dr. Mymon Goldstein, Princeton University, for making available to him the stimulus materials used in the present study 